\title{
Autoregulated Induction of the Acute-Phase Response Transcription Factor Gene, agp/ebp
}

\author{
CHING-JIN CHANG, ${ }^{1}$ BIN-JON SHEN,${ }^{2}$ and SHENG-CHUNG LEE ${ }^{1,3}$
}

\begin{abstract}
AGP/EBP (C/EBP $\beta)$ is a key transcription factor responsible for transcriptional induction of many acute-phase protein genes. To characterize the regulation of this gene, we have isolated the mouse genomic DNA and sequenced the 5 '-regulatory region. Using nuclear extracts from lipopolysaccharide (LPS)stimulated or unstimulated mouse liver, three protein factor-binding motifs, UF1( -376 to -352$)$, UF2 $(-254$ to -223$)$, and UF3( -220 to -190$)$, as well as two Sp1 motifs $(-309$ to -277 , and -264 to -241$)$ were identified by DNase I footprinting assays. Biochemical analysis has shown that the AGP/EBP protein can bind to UF1 and UF2 sites, whereas an ubiquitous factor of unknown identity can bind to the UF3 site. Functional characterizations indicate that all of these factors play a major role in AGP/EBP induction. Thus, the agp/ebp gene is autoregulated during the acute-phase response.
\end{abstract}

\section{INTRODUCTION}

D URING THE LAST FEW YEARS, the 5 '-flanking regions of many acute-phase protein genes have been studied extensively. The goal most of these studies was to identify regulatory elements required for cytokine-mediated induction of these genes. One type of cytokine response element has been found in the promoters of several acute-phase protein genes, representing binding sites for multiple members of the C/EBP family of transcription factors (Akira and Kishimoto, 1992). We have previously cloned and identified a key nuclear transcription factor, AGP/EBP, which is responsible for induction of the alpha-1 acid glycoprotein gene (Chang et al., 1990; Lee et al., 1993) and other acute-phase protein genes (Isshiki et al., 1991; Alam et al., 1992) during acute inflammation. AGP/EBP is a mouse liver-enriched transcription factor that belongs to the C/EBP transcription factor family. Several closely related or homologous factors from other species have been described, such as LAP (Descombes et al., 1990), IL-6DBP (Poli et al., 1990), C/EBPß (Cao et al., 1991), and CRP2 (S.C. Williams et al., 1991) from rat and NF-IL6 (Akira et al., 1990) from human. $C / E B P \beta$ is the common name for these factors isolated from different sources.

The regulation of AGP/EBP expression is very complex. In mouse liver and several other tissues, AGP/EBP expres- sion is highly induced at both mRNA and protein levels during acute inflammation. Expression can also be induced by treating the animals with lipopolysaccharide (LPS) or recombinant cytokines, e.g., interleukin-6 (IL-6), and IL-1 (Akira and Kishimoto, 1992). The agp/ebp gene has been shown to encode three polypeptides through a novel translational mechanism employing three in-frame translation initiation codons (Descombes and Schibler, 1991). Among these three proteins, the larger two are activators, whereas the smaller one functions as a repressor. The activator-to-repressor ratio varies during liver differentiation.

This may result in the dynamic regulation of the activity of AGP/EBP and its closely related members. Furthermore, IL-6 treatment can result in post-translational modifications of IL-6DBP (Poli et al., 1990). AGP/EBP has been shown to be modified by phosphorylation under different physiological conditions (Wegner et al., 1992; Nakajima et al., 1993; Trautwein et al., 1993). Another example of the regulation of NF-IL6 activity involves the interaction of NF-IL6 and the glucocorticoid receptor (P. Williams et al., 1991; Nishio et $a l ., 1993)$. This interaction between proteins may be responsible for the induction of certain genes (i.e., $\alpha-1$ acid glycoprotein) by glucocorticoids.

AGP/EBP is a key molecule required for the LPS induction of various cellular genes, and recent data have indicated that members of the AGP/EBP family play important roles in

\footnotetext{
${ }^{1}$ Institute of Biological Chemistry, Academia Sinica, ${ }^{2}$ Institute of Biochemical Sciences, and ${ }^{3}$ Institute of Molecular Medicine, Dr. Huei-Lang Tsai Memorial Laboratory, College of Medicine, National Taiwan University, Taipei, Taiwan.
} 
the consolidation of long-term facilitation in Aplysia (Alberini et al., 1994) and in the induction of the c-fos protooncogene (Metz and Ziff, 1991). It is extremely important to have a better understanding of how the agp/ebp gene is regulated transcriptionally. In this report, we present data on factors involved in the regulation of $a g p / e b p$ gene transcription, especially its autoregulation during acute inflammation.

\section{MATERIALS AND METHODS}

\section{Isolation of genomic DNA for AGP/EBP}

Mouse genomic DNA was digested with Eco RI. The restricted fragments were separated by agarose gel. Fragments of $4-8 \mathrm{~kb}$ in size were recovered from the gel and used for construction of a $\lambda$ gt 10 library. A recombinant $\lambda$ clone containing the AGP/EBP gene was obtained by probing with an AGP/EBP cDNA probe. This genomic DNA fragment was characterized by restriction mapping and by partial DNA sequencing. Subsequently, a 5-kb Eco RI fragment containing the entire coding region of AGP/EBP and a 3-kb upstream regulatory sequence were subcloned into pGEM4 vector (Promega).

\section{Plasmids and constructs}

The plasmids pCMV-AGP/EBP and AGP-CAT were described in our earlier work (Lee et al., 1993). An Eco RI-Sph I fragment spanning from $-3 \mathrm{~kb}$ to +82 was isolated from genomic AGP/EBP DNA and cloned into the pGEM4 vector (Promega). This fragment was used for generating a series of $5^{\prime}$ deletion fragments using $\mathrm{Bal}$-31 digestion. The following CAT constructs were obtained: $-685 /+82-\mathrm{CAT},-390 /$ +82-CAT, $-343 /+82$-CAT, $-250 /+82$-CAT, $-156 /+82-$ CAT, $-76 /+82$ CAT, and $-44 /+82$-CAT. pCAT-basic and pCAT-promoter vectors were purchased from Promega.

$-390 \mathrm{mtUF} 1 /+82-\mathrm{CAT}$ and $-390 \mathrm{mtUF} 2 /+82-\mathrm{CAT}$ were generated by site-directed mutagenesis using the following primers: $5^{\prime}$-GATCTGAGTCCCAAG-3' and 5'-GCTGGCGTTCCCCGCGTCCGT-3'. pAcSp1 (a Drosophila cell Spl expression vector) was obtained from Dr. R. Tjian's laboratory.

\section{Cell cultures and transfections}

HepG2 cells were grown in Dulbecco's modified Eagle medium (DMEM) with $10 \%$ fetal calf serum. HepG2 cells were plated on $6-\mathrm{cm}$ petri dishes at about $50 \%$ confluence when used for transfections. Transfections were performed using the calcium phosphate precipitation method. Twentyfour hours after transfection, plates were rinsed with DMEM and DMEM $/ 10 \% \mathrm{FCS}$ was added. The cells were harvested $48 \mathrm{hr}$ post-transfection and $40 \mu \mathrm{g}$ of protein from the cellular extracts was used for chloramphenicol acetyltransferase (CAT) assays. The Schneider cell line SL.2 was cultured in Schneider's Drosophila medium (GIBCO).

\section{Nuclear extracts and DNase I footprinting assays}

Nuclear extracts from normal or LPS-treated mouse/rat liver were prepared as described (Lee et al., 1993). For
DNase I footprinting assays, nuclear extracts from liver were used. Recombinant AGP/EBP was used as a control (Lee $e t$ $a l ., 1993)$. The end-labeled probe was derived from the -390 to +82 fragment of the AGP/EBP 5' upstream regulatory region. Preliminary experiments indicated that sequences between -685 and -390 do not have detectable trans-acting factor binding. Therefore, fragment containing -390 to +82 was chosen for footprinting studies. Purified Spl from HeLa cells was obtained from Promega.

\section{Bandshift assays}

For bandshift assays, nuclear extracts from unstimulated and LPS-stimulated mouse livers were incubated in a $20-\mu$ l reaction mixture containing $20 \mathrm{~m} M$ HEPES pH 7.5, $50 \mathrm{mM}$ $\mathrm{NaCl}, 0.1 \mathrm{~m} M$ EDTA, $0.5 \mathrm{~m} M$ dithiothreitol, $10 \%$ glycerol, $1 \mu \mathrm{g}$ of poly $(\mathrm{dI}-\mathrm{dC} \cdot \mathrm{dI}-\mathrm{dC})$, and $0.5-1.0 \mathrm{ng}(10,000-$ $20,000 \mathrm{cpm}$ ) of labeled synthetic oligodeoxynucleotides. The sequences of these double-stranded oligodeoxynucleotides were (sense strand is shown): UF1, 5'-GATCAGGAACGATCTGTTTCCCAAGAGTT-3'; UF2, 5'-GATCGAAGGGGGCGGGC TGGCGT CACCCGCGTCCGT-3'. For the supershift assays, monoclonal or polyclonal antibodies to $\mathrm{AGP} / \mathrm{EBP}$ were added to the reaction mixture $10 \mathrm{~min}$ before terminating the reaction.

\section{Nuclear run-on assays}

Nuclear fractions were prepared as described (Lee et al., 1993). Nuclear pellets were resuspended in storage buffer (40\% glycerol, $40 \mathrm{mM}$ Tris- $\mathrm{HCl} \mathrm{pH} 7.9,10 \mathrm{mM} \mathrm{MgCl} 2,280$ $\mathrm{m} M \mathrm{KCl}, 4 \mathrm{~m} M$ DTT, $2 \mathrm{~m} M \mathrm{MnCl}_{2}$ ) at $10^{7}$ nuclei $/ 50 \mu \mathrm{l}$. The total nuclear run-on experiment was performed in a reaction mixture of $100 \mu \mathrm{l}$ containing $100 \mu \mathrm{Ci}$ of $\left[\alpha-{ }^{32} \mathrm{P}\right] \mathrm{UTP}(800$ $\mathrm{Ci} / \mathrm{mmole})$. The ${ }^{32} \mathrm{P}$-labeled RNA probe was hybridized with nitrocellulose strips carrying slot-blotted DNA $(2 \mu \mathrm{g}$ per slot) for 3 days.

\section{RESULTS}

\section{Mouse agp/ebp gene}

To study the transcriptional regulation of the agp/ebp gene, nuclear run-on assays using nuclear preparations from mouse liver with or without LPS treatment were performed. The transcription rate of AGP was dramatically induced when the mouse was treated with LPS. AGP/EBP was also stimulated albeit to a lesser degree than AGP (Fig. 1). These results indicate that both $a g p$ and $a g p / e b p$ gene expression are transcriptionally regulated when the animal is treated with LPS. To identify regulatory elements involved in transcriptional regulation of the agp/ebp gene, we cloned a genomic DNA containing the entire agp/ebp gene $(5 \mathrm{~kb})$ including $3 \mathrm{~kb}$ of its $5^{\prime}$ upstream sequence. We mapped its restriction sites and determined the sequence containing the -685 upstream region. The sequence from -685 to +82 is shown in Fig. 2A. To identify the regions that are important for the AGP/EBP promoter activity, we prepared nested deletions of the 5 '-flanking sequence using $\mathrm{Bal}-31$ and linked 


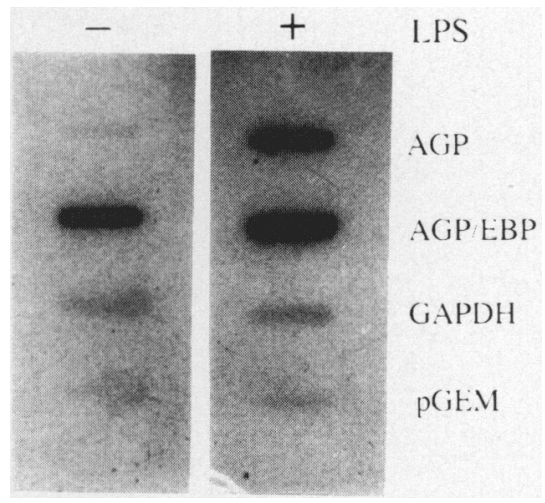

FIG. 1. Nuclear run-on analysis of mouse liver with or without LPS treatment. Liver nuclear fractions were prepared from normal $(-)$ and LPS-stimulated (+) livers. LPS (100 $\mu \mathrm{g} / 10-15$ grams of BALB/c mouse) treatment was performed by i.p. injection for $4 \mathrm{hr}$. Specific DNAs bound to the nitrocellulose membrane were hybridized with $\left[\alpha-{ }^{32} \mathrm{P}\right] \mathrm{UTP}$-labeled run-on probes.

them to the CAT reporter gene. Plasmids derived from these constructs were used for transfection assays. The results suggest that the region between -685 and -390 contains a negative element(s) while that between -390 and -44 contains positive elements (Fig. 2B).

\section{Trans-acting factors involved in the agp/ebp gene} regulation

To demonstrate that the agp/ebp gene transcription is regulated by different trans-acting factors, we performed DNase I footprinting analysis using fragment derived from the -390 to $+825^{\prime}$ regulatory region of the AGP/EBP gene as a probe. Nuclear extracts prepared from normal and LPS-treated mouse livers were prepared and used for footprinting assays. We detected two prominent protection regions [from -376 to -352 (UF1), and -220 to $-190(\mathrm{UF} 3$ )], together with two weak protection regions $(-309$ to -277 , and -264 to -241 ) within this sequence (Fig. 3A, lanes 2 and 3). Nuclear extract from LPS-treated livers was used for footprinting assays; a prominent protection region spanning from -254 to -223 (UF2) was also seen in addition to the UF1 and UF3 sites (Fig. 3A, lanes 4 and 5).

The nucleotide sequence of the two weak protection regions $(-309$ to -277 and -264 to -241$)$ suggests that they are potential binding sites for transcription factor Spl. Therefore, purified Spl was shown to bind to these sequences by a footprinting assay (Fig. 3B, lanes 1-4). One of the two regions $(-264$ to -241$)$ overlaps with UF2. Because the sequence of UF1 is very similar to the AGP/EBP DNA-binding consensus motif, we tested the footprinting pattern of recombinant AGP/EBP. The results demonstrate that low amounts of recombinant AGP/EBP (10 ng) protect the UF1 region, whereas high amounts additionally protect the UF2 region (Fig. 3B, lanes 5-8). These results are consistent with the results obtained from the nuclear extract, i.e., the UF2 motif can be recognized by induced nuclear extract in which AGP/EBP (or other factors) activity or level is highly increased.

\section{$A G P / E B P$ protein binds to the $U F 1$ and $U F 2$ regions and activates agp/ebp gene expression}

To characterize further the protein factors that bind to UF1 and UF2 motifs, we synthesized oligonucleotides corresponding to these regions and used them for both competition and bandshift assays. Nuclear extracts from LPS-treated liver cells was used for footprinting analysis. Factors that bind to both UF1 and UF2 could be independently competed by oligonucleotides from UF1, UF2, and the AGP/EBP binding motif $(\mathrm{C}, \mathrm{D}$, and $\mathrm{E}$ motifs from the AGP promoter; Lee et al., 1993). An oligonucleotide recognized by Spl was used as a negative control (Fig. 4A, lanes 4-9). Furthermore, nuclear extracts from both normal and LPS-treated liver, together with monoclonal and polyclonal antibodies against AGP/EBP, were tested with a gel mobility-shift assay. The protein-DNA complex formed by the UF1 oligonucleotide and protein(s) from both normal and LPS-stimulated nuclear extracts could be supershifted by AGP/EBP antibodies (Fig. 4B). In contrast, only the complex formed by the UF2 oligonucleotide and protein(s) from LPS-stimulated nuclear extract, but not normal nuclear extract, were supershifted (Fig. 4C). Consequently, these results indicate that UFI- and UF2-binding protein complexes share the common AGP/ EBP factor present in the LPS-stimulated liver nuclear extracts.

To determine whether the partial palindromic UF1 $\left(5^{\prime}\right.$ GTTTCCCAAG-3') and UF2 ( $5^{\prime}$-CTGGCGTCAC- $3^{\prime}$ ) motifs are indeed recognized by AGP/EBP, we synthesized these oligonucleotides and used them as probes for bandshift assays. Complexes formed by these short oligonucleotides and nuclear extracts were also recognized by AGP/EBP antibodies (data not shown).

To dissect further the factor that was induced by LPS, we performed a footprinting analysis using probes containing the UF1- or UF2-mutated sequence (in which the critical nucleotides of the AGP/EBP binding motif was destroyed; see Fig. 5, upper panel) and LPS-treated liver nuclear extracts. When mutated UF1 or UF2 probe was used, the footprinting protection of UF1 or UF2 was abolished (Fig. $5)$. These results suggest that the factors binding to these two motifs independently, and the binding of AGP/EBP is essential for UF1 and UF2 footprints.

Therefore, we tested the possibility that AGP/EBP is involved in the induction of its own gene. We cotransfected HepG2 cells with various deletion constructs of AGP/EBPCAT and pCMV-AGP/EBP or pCMV-C/EBP $\alpha$. Both AGP/ $\mathrm{EBP}$ and $\mathrm{C} / \mathrm{EBP} \alpha$ can trans-activate the AGP/EBP promoter, but cannot trans-activate the pCAT-promoter (Fig. $6 \mathrm{~A})$. When the UF1 site was deleted (-250-CAT), only slight decrease in AGP/EBP activation was observed. But when both UF1 and UF2 sites were deleted (-156-CAT), the activation effect of AGP/EBP was affected dramatically. In addition to the above-mentioned AGP/EBP-binding sites, the sequence in the TATA box that can be recognized by recombinant AGP/EBP (eata not shown; also see Lee et al., 
A

-684 GTGACTCACC CAGACACAGT GTGGCAGAAC CCCCAGCCCT GCCACCTTCA

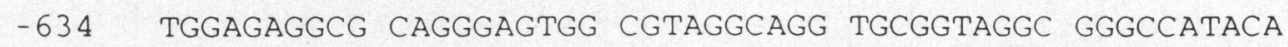

-584 TAgGgtgGag GGCTGGGatC CAGGACAgCG AGCATCCCCG GGgtgGgCGT

-534 GCACCTGGAG AgTtCTGCTT CCCAGGACTT GGGGGGGGgG TCCCAGAGGT

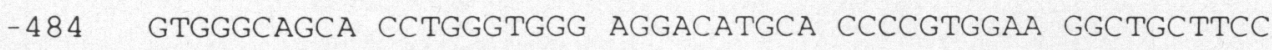

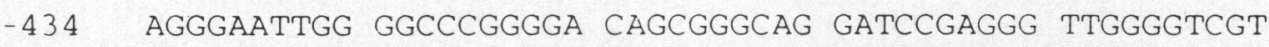

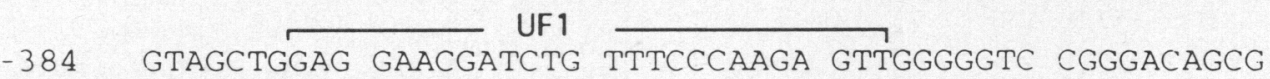

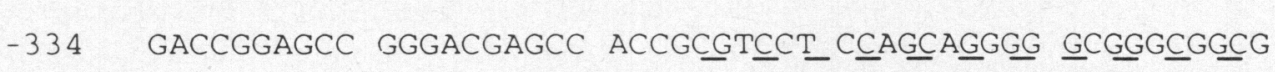

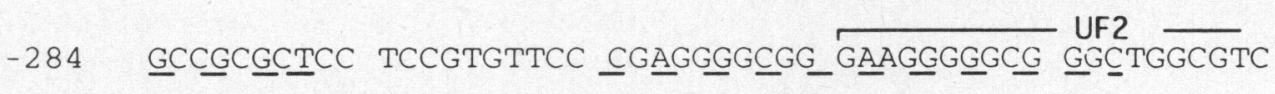

-234 ACCCGCGTCC GTGGCCATCG CGGGGCTGGC GGGACGCCCG GGTCACCGCT

-184 CAGCCTCCCG CGCGAGGACC CCCGCCGCGC CCCACTCCCC GCCGCGCCCT

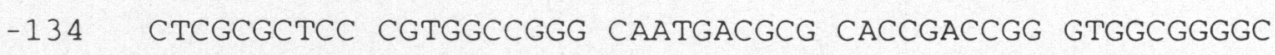

- 84 GGCGGGAGGG GCCCCAGCGT GACGCAGCCC GTTGCCAGGC GCCGCCTtat

- 34 AAACCTCCCG CTCGGCCGCC GCCGCGCCGA GTCCGAGCCG CGCACGGGAC

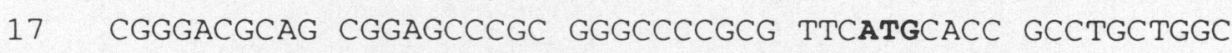

B 67 CTGGGACGCA GCATGC
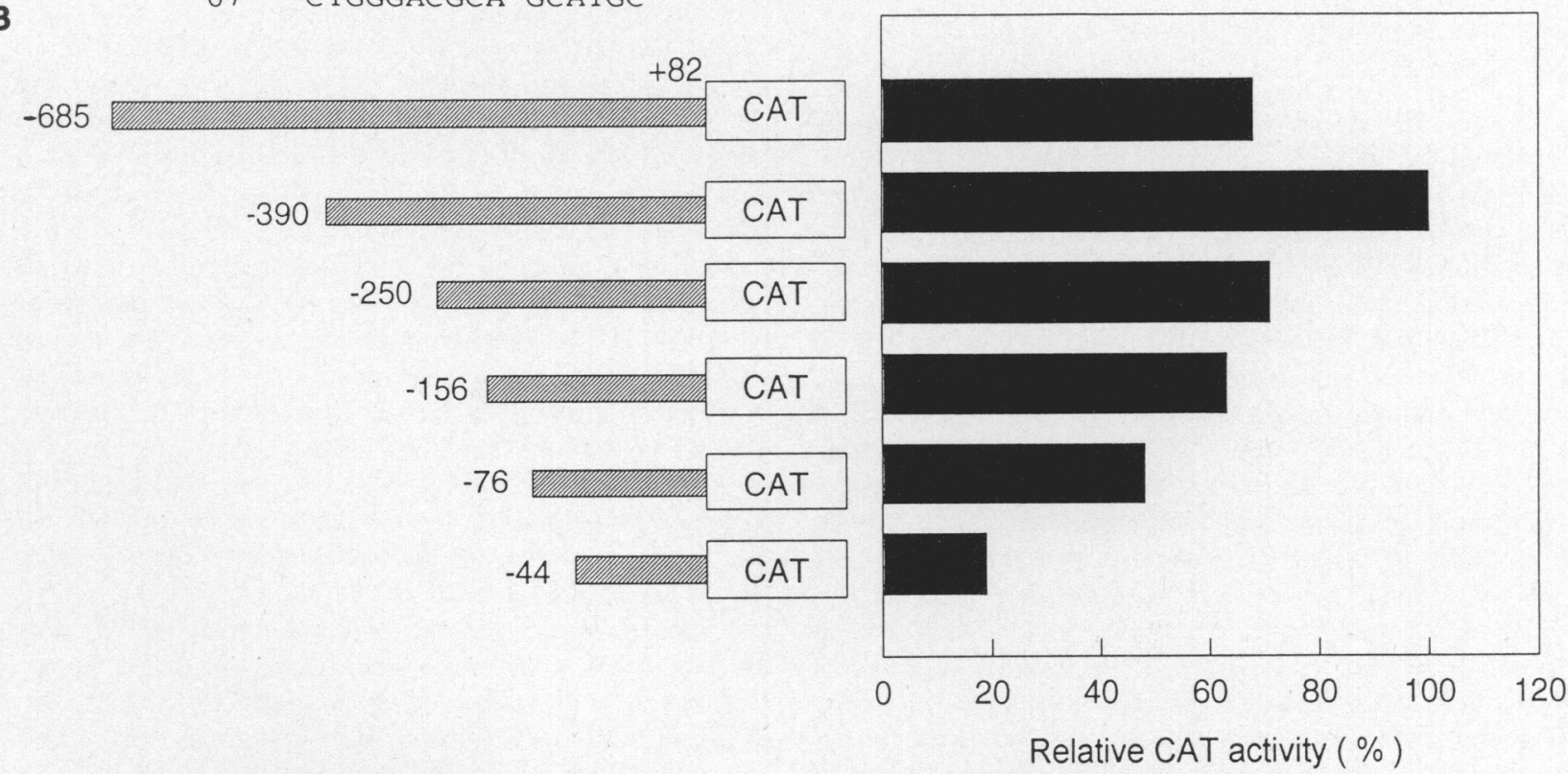

FIG. 2. Sequence and functional analysis of agp/ebp gene $5^{\prime}$ regulatory regions. A. Nucleotide sequence of the 5 '-flanking region of agp/ebp gene. The transcription initiation site is indicated as +1 . The TATA box is underlined. The first translation initiation codon is in boldfaced letters. The footprinting-protected regions of UF1, UF2, and UF3 are indicated by overlining, and $\mathrm{Spl}$ binding sites are indicated by dashed underlines. B. Transfection analysis of serially deleted AGP/EBP promoter linked to CAT reporter gene. HepG 2 cells were seeded in $60-\mathrm{mm}$ petri dishes and transfected with $5 \mu \mathrm{g}$ of AGP/EBP-CAT plasmids. Reporter activity is shown as percent conversion relative to $100 \%$ activity obtained with $(-390)$ AGP/EBP-CAT. Data are representatives of at least three independent experiments. 


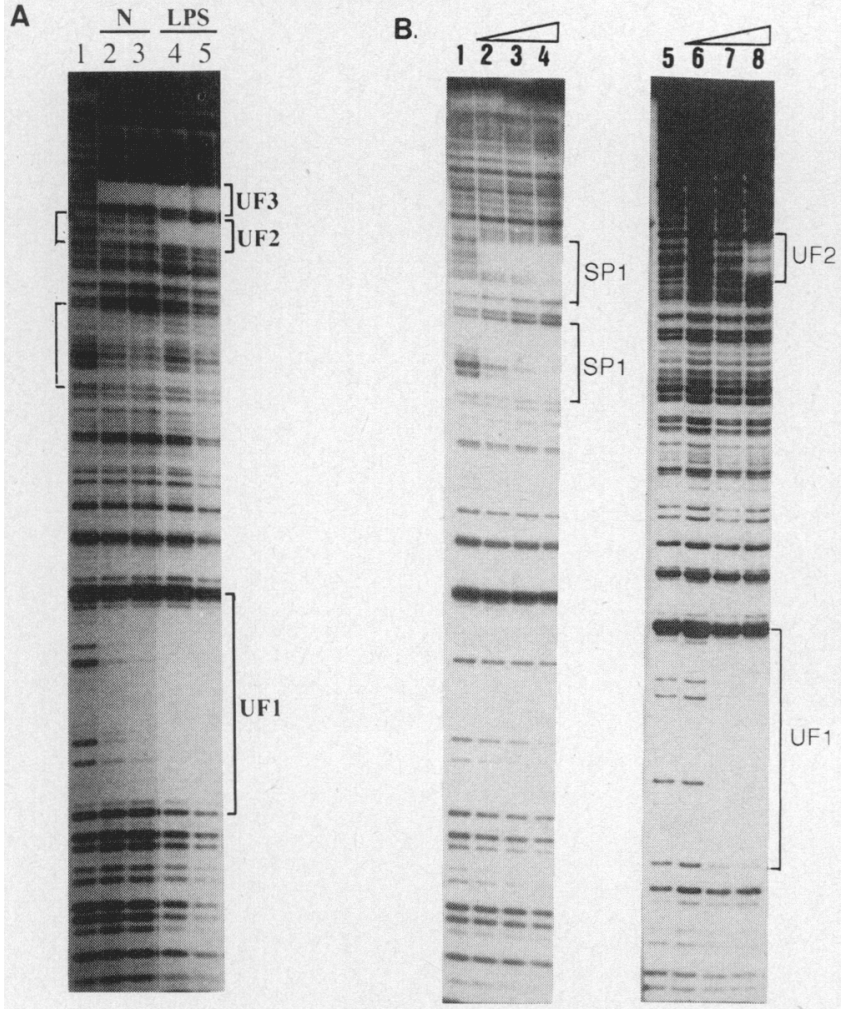

FIG. 3. DNase I footprinting analysis of the 5 '-flanking sequence of $a g p / e b p$ with nuclear extracts from mouse liver, recombinant AGP/EBP, and purified Spl. A. Probe containing -390 to +82 was incubated with 10 and $20 \mu \mathrm{g}$ of normal (lanes 2 and 3) and LPS-treated lanes 4 and 5) liver nuclear extracts. Lane 1 is a BSA control. The left brackets indicate two weak protection regions $(-309$ to $-277,-264$ to -241 ) and right brackets represent the UF1 ( -376 to -352$)$, UF2 $(-254$ to -223$)$, and UF3 $(-220$ to -190$)$ protection sites. B. Purified Spl and recombinant AGP/EBP were used for the footprinting experiment. Lanes 1 and 5, BSA controls; lanes $2-4$, increasing amounts of $\operatorname{Spl}(6,12$, and $24 \mathrm{ng})$; lanes $6-8$, recombinant AGP/EBP $(10,20$, and $40 \mathrm{ng})$. The probe is the same as in A.

1993) may be responsible for the observed low activation of -156-CAT and -44-CAT by pCMV-AGP/EBP or pCMV$\mathrm{C} / \mathrm{EBP} \alpha$ (Fig. 6A). The stimulatory effect of pCMV-AGP/ EBP on wild-type-, mutant UF1-, or mutant UF2-AGP/EBPCAT was further investigated by cotransfection of these plasmids into HepG2 cells. The results indicate that both mutant UF1- and UF2-AGP/EBP-CAT respond to AGP/EBP less well than the wild-type-AGP/EBP-CAT (Fig. 6B). These data suggest that AGP/EBP is involved in the transcriptional activation of $a g p / e b p$ gene during acute inflammation.

\section{The role of Spl in agp/ebp gene expression}

There are two motifs in the agp/ebp 5'-flanking region recognized by $\mathrm{Spl}$. We tested the involvement of $\mathrm{Sp} 1$ in activation of the agp/ebp gene. The SL. 2 Schneider cell line was used for cotransfection assays with various constructs, including an Sp1 expression vector, pAcSp1, and AGP/EBPCAT. Spl can activate the agp/ebp gene (Fig. 7A), but cannot trans-activate the agp gene (which was used as a control). The promoter region of AGP/EBP is GC-rich, which may be responsible for the activation of a minimal promoter sequence such as $-44-C A T$. One of the Sp1 motifs $(-264$ to -241 , overlapping with UF2) is undetectable in the presence of nuclear extracts from LPS-treated liver but detectable when nuclear extract from normal liver was used (Fig. 3). Detailed footprinting analysis was performed using fixed amounts of purified Sp1 and increasing amounts of nuclear extracts from normal or LPS-treated liver cells (the level of AGP/EBP in these two nuclear extracts has been adjusted to the same amount by Western blot assay). This experiment clearly established that factors derived from the LPS-treated liver could abolish the Spl binding to the motif overlapped with UF2, but normal liver nuclear extract could not (Fig. 7B). This suggested that, in addition to AGP/EBP, the UF2 protein complex contained other LPS-stimulated factors. This possibility will be further discussed.

\section{DISCUSSION}

\section{$A G P / E B P$ is involved in transcriptional regulation of the agp/ebp gene}

Two lines of evidence suggest that AGP/EBP mediates the initiation of transcription of the agp/ebp gene: (i) biochemical characterization of trans-acting factors from normal and LPS-treated liver nuclear extracts indicate (a) that AGP/EBP is involved in the binding to AGP/EBP upstream regulatory sequence(s) and (b) that the recombinant AGP/EBP can recognize both UF1 and UF2 motifs. (ii) differences between the footprinting patterns of normal and LPS-liver nuclear extracts demonstrate that the UF2-binding factor exists only in the LPS-treated but not in the normal liver nuclear extracts. The UF2-binding factor can be recognized by antibodies to AGP/EBP as demonstrated by gel mobilityshift assay. Thus, the UF2-binding factor is an acute inflammation-induced nuclear factor containing AGP/EBP. In contrast to the up-regulation of the agp/ebp gene during the acute-phase response, the $c / e b p \alpha$ gene is down-regulated (Isshiki et al., 1991). However, clebp $\alpha$ gene expression is increased during differentiation of 3T3-L1 preadipocytes into adipocytes (Christy et al., 1991). Thus, there are some similarities between agp/ebp gene regulation during the acute-phase response and clebpa gene regulation during 3T3-L1 differentiation. The c/ebp $\alpha$ gene is autoregulated by its own product during 3T3-Ll differentiation (Christy et al., 1991; Legraverend et al., 1993). The sequence located at -198 to -176, TCAGTGGGCGTTGCGCCAC, which is recognized by $\mathrm{C} / \mathrm{EBP} \alpha$, is strikingly similar to the UF2 sequence in the agp/ebp promoter GGGGGCGGGCTGGCGTCAC$\mathrm{CCGC}$. The sequence in the UF2 region must play an important role in LPS-induced agp/ebp gene expression that is much like the importance of the -198 to -176 sequence in the c/ebp $\alpha$ promoter for $\mathrm{C} / \mathrm{EBP} \alpha$ production during 3T3-L1 differentiation. The nucleotide sequence of -256 to -234 in the $5^{\prime}$ regulatory region of $\mathrm{C} / \mathrm{EBP} \alpha$ is CUP/Sp1-like GT box element (Vasseur-Cognet, and Lane, 1993). During differentiation of 3T3-L1 preadipocytes into adipocytes, CUP activity decreases as expression of $\mathrm{C} / \mathrm{EBP} \alpha$ increases. There may be a parallelism between the decrease of CUP/Spl activity upon the induction of $\mathrm{C} / \mathrm{EBP} \alpha$ during adipocyte differentiation and the disappearance 
A

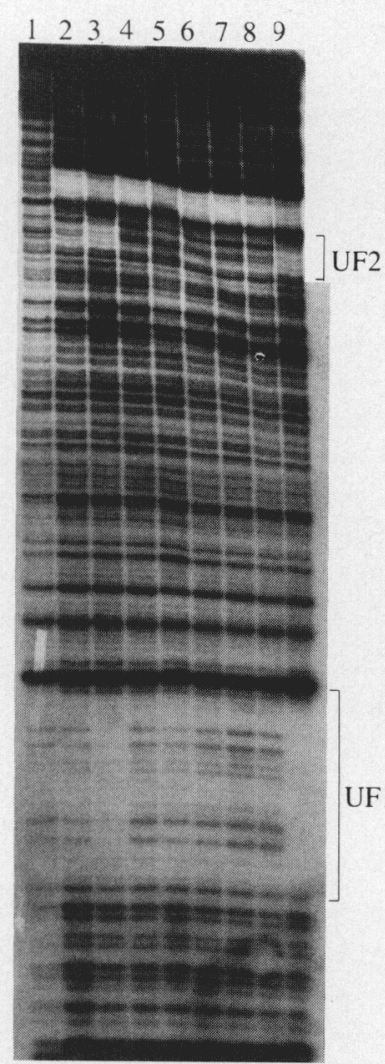

B.

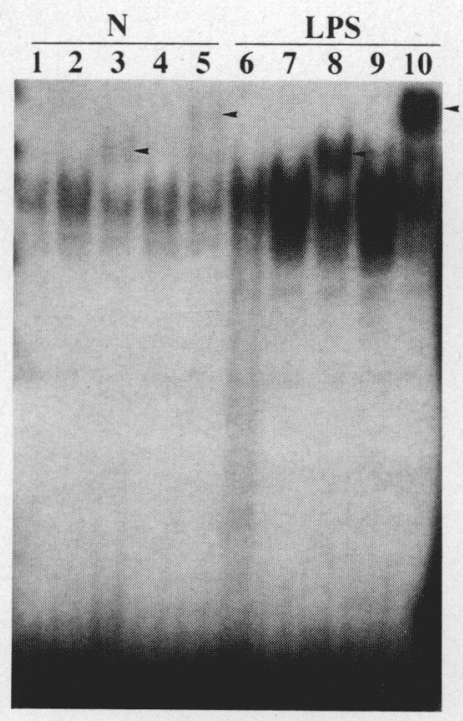

c.

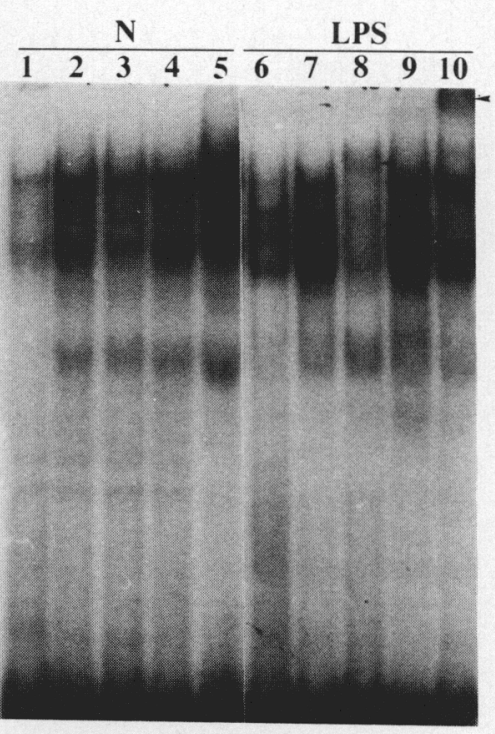

FIG. 4. Biochemical and serological characterizations of UF1- and UF2-binding factors. A. Footprinting competition analysis of binding specificity of UF1 and UF2 elements. The probe is same as in Fig. 3; nuclear extracts are from LPS-treated mouse liver. Lane 1, BSA control; lane 2, $10 \mu \mathrm{g}$ of nuclear extract; lanes 3-9, $20 \mu \mathrm{g}$ of nuclear extracts. Lanes 4-9 are in the presence of $40 \mathrm{ng}$ of oligonucleotide competitors of UF1, UF2, C, D, E elements (AGP/EBP binding sites of AGP gene; Lee et al., 1993), and Sp1. B. Gel retardation of antibodies supershift assay. A 1-ng amount of UF1 oligonucleotide probe was incubated with nuclear extracts from normal (lanes 1-5) or LPS-stimulated (lanes 6-10) mouse liver. Lanes 1 and 6, Controls (without antibody); lanes 2 and 7, nonspecific antibody controls; lanes 3 and 8, in the presence of AGP/EBP monoclonal antibody; lanes 4 and 9, rabbit preimmune serum controls; lanes 5 and 10, AGP/EBP polyclonal antibody. C. A 1-ng amount of UF2 oligonucleotide probe was used instead of UF1, and the experimental conditions were the same as B.

or diminishing of Sp1 footprinting activity upon the induction of $\mathrm{AGP} / \mathrm{EBP}$ during the acute-phase response.

A number of homeotic genes, proto-oncogenes, and transcriptional factor genes have been shown to be autoregulated by their own products (Serfling, 1989). For example, the jun proto-oncogene is positively autoregulated by its product, Jun/AP1 (Angel et al., 1988). Fos can repress its own transcription (Sassone-Corsi et al., 1988; Konig et al., 1989; Schonthal et al., 1989). Also the c-myc gene is negatively autoregulated by its own product (Penn et al., 1990) and Pit-1/GHF-1, MyoD, and NF-kB are involved in their own regulation (Thayer et al., 1989; Chen et al., 1990; Ten et al., 1992). These examples further demonstrate that it is not unusual that the agp/ebp gene is autoactivated by its own product or by closely related C/EBP family members.

\section{Inducible versus constitutive expression of the agp/ebp gene}

AGP/EBP is a liver-enriched transcription factor. Several trans-acting factors, such as $\mathrm{C} / \mathrm{EBP} \alpha, \mathrm{AGP} / \mathrm{EBP}, \mathrm{Sp} 1$, and
UF3-binding factor, have been shown to be involved in AGP/EBP transcriptional regulation. The UF1-bound $\mathrm{C} / \mathrm{EBP} \alpha$ (antibody supershift assay, data not shown) and AGP/EBP, in conjunction with Sp1 and the UF3-binding factor, may constitute the predominant factors that are necessary for the constitutive expression of the agp/ebp gene. This is supported by two lines of evidence: (i) the level of $\mathrm{Sp} 1$ and the UF3-binding factor remains relatively constant before and after LPS treatment (data not shown) and (ii) $\mathrm{C} / \mathrm{EBP} \alpha$ is very abundant in liver cells under normal physiological conditions, suggesting that these factors are crucial in maintaining the constitutive expression of hepatic $a g p /$ $e b p$. AGP/EBP itself may form heterodimers with $\mathrm{C} / \mathrm{EBP} \alpha$ or members of the $\mathrm{C} / \mathrm{EBP}$ family, thus exerting its regulatory function for its own gene.

When UF2 factors are induced by LPS treatment, one of the $\mathrm{Sp} 1$ footprinting patterns $(-264$ to -241$)$ disappears. In contrast to this, two regions $(-309$ to -277 and -264 to -241 ) can clearly be recognized by the purified Sp1 (Fig. 3B). The UF2-binding factors may inhibit the Sp1 binding by steric hindrance or competition. The mere presence of the 


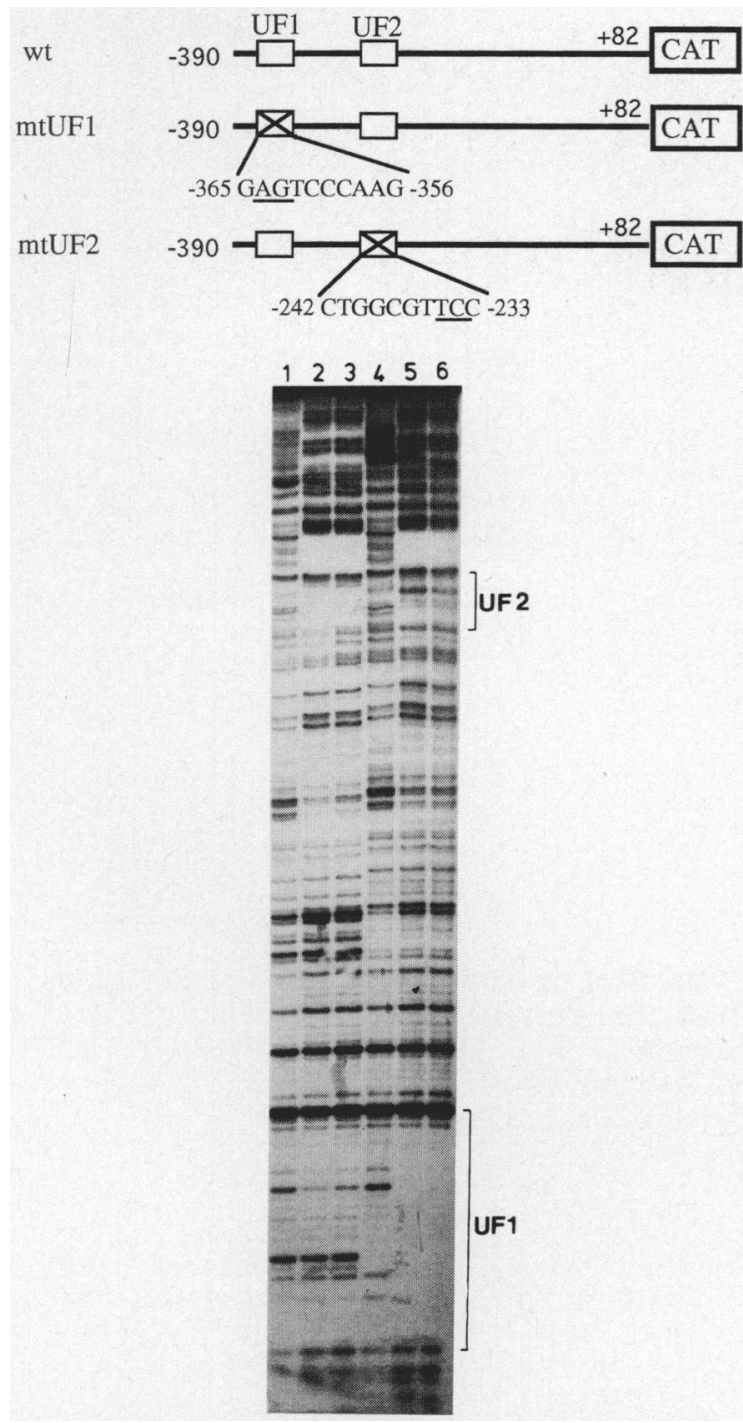

FIG. 5. DNase I footprinting analysis of mutant AGP/EBP promoter probe generated by site-directed mutagenesis. Sequences of the mutated AGP/EBP binding motif of mutant UF1 and mutant UF2 are shown in the upper panel. Both probes were derived from -390 to +82 fragments. Footprinting patterns are shown in the lower panel. Mutant UF1 (lanes 1-3) or mutant UF2 (lanes 4-6) probe was incubated with mouse liver nuclear extract prepared from LPS-stimulated animal $(10 \mu \mathrm{g}$ for lanes 2 and 5; $20 \mu \mathrm{g}$ for lanes 3 and 6). Lanes 1 and 4 are controls.

Sp1 motif does not constitute obligatory binding by $\mathrm{Sp} 1$ in the nuclear extract. We have shown that AGP/EBP is involved in UF2 binding. The amount of AGP/EBP protein increases during LPS stimulation (data not shown). Under physiological conditions, C/EBP $\alpha$ or its closely related member is bound to UF1 and may function in regulating the basal transcriptional activity of the agp/ebp gene. During LPS-stimulated conditions, increasing amounts of AGP/EBP and its heterodimers with other factors may bind to the UF2 region and may be responsible for agp/ebp gene induction. Recently, we have obtained some evidence indicating that
A
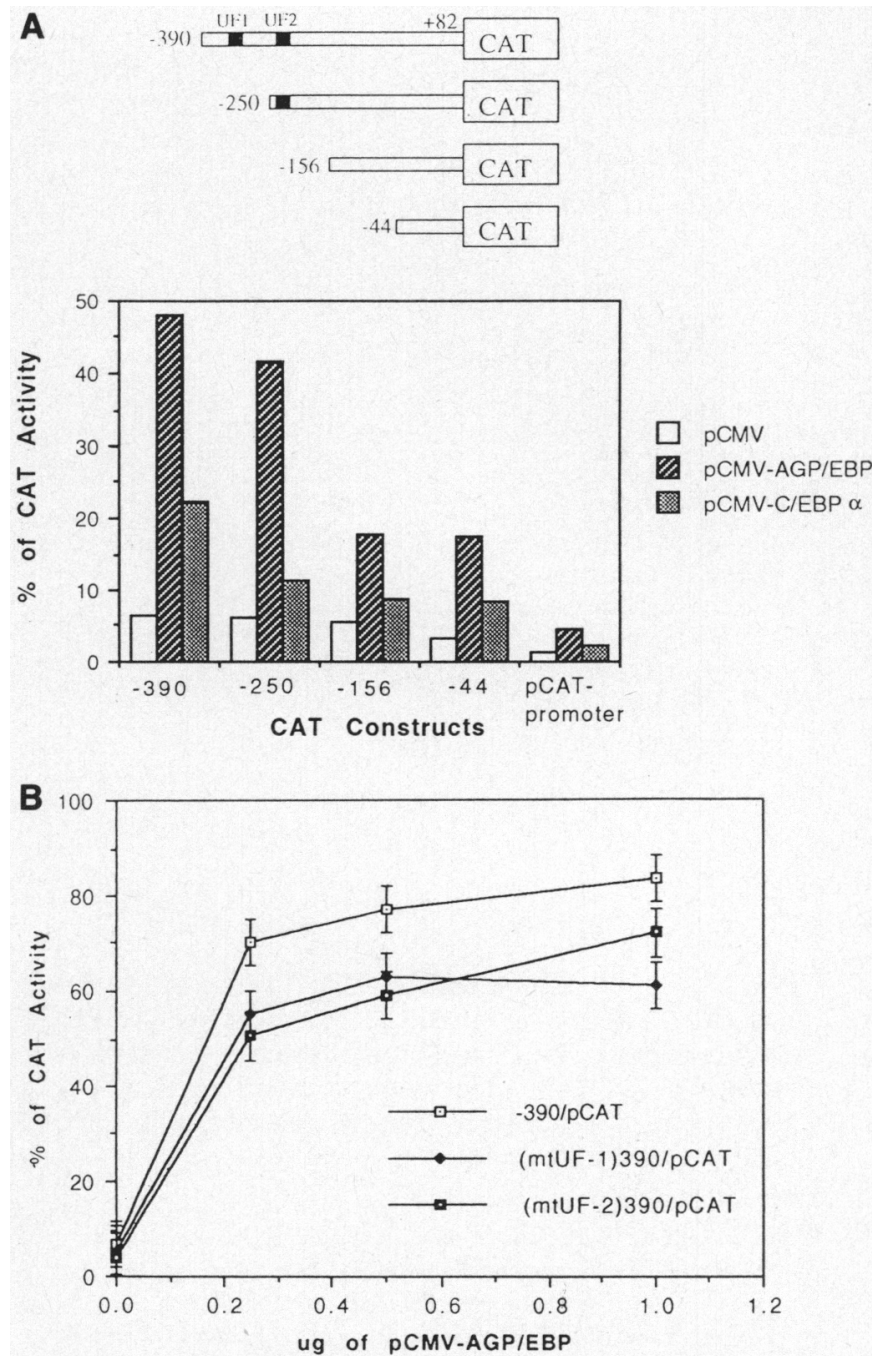

FIG. 6. Activation of AGP/EBP promoter by AGP/EBP or $\mathrm{C} / \mathrm{EBP} \alpha$ expression vector. A. HepG2 cells were transiently transfected with $2 \mu \mathrm{g}$ of AGP/EBP-CAT or pCAT-promoter (control) reporter plasmids in the presence of $0.2 \mu \mathrm{g}$ of pCMV-AGP/EBP or pCMV-C/EBP $\alpha$ expression vector, or pCMV control. Values are percentages of the CAT conversion. B. Cotransfection experiments using plamids $(2 \mu \mathrm{g})$ derived from wild-type AGP/EBP promoter $(-390$ to +82$)$, mtUF1-, or mtUF2-CAT reporter and increasing amounts $(0.25,0.5$, and $1.0 \mu \mathrm{g})$ of pCMV-AGP/EBP expression vector. Data are representatives of three independent experiments.

the transcription factors of CREB/ATF family may be involved in UF2-mediated function (unpublished data).

\section{ACKNOWLEDGMENTS}

We thank Dr. Stefan Gruenwald for reviewing this manuscript and J.L. Chen of Dr. R. Tjian's laboratory for the pAcSp1 plasmid. This research was supported by grants from the National Science Council, ROC. 
A

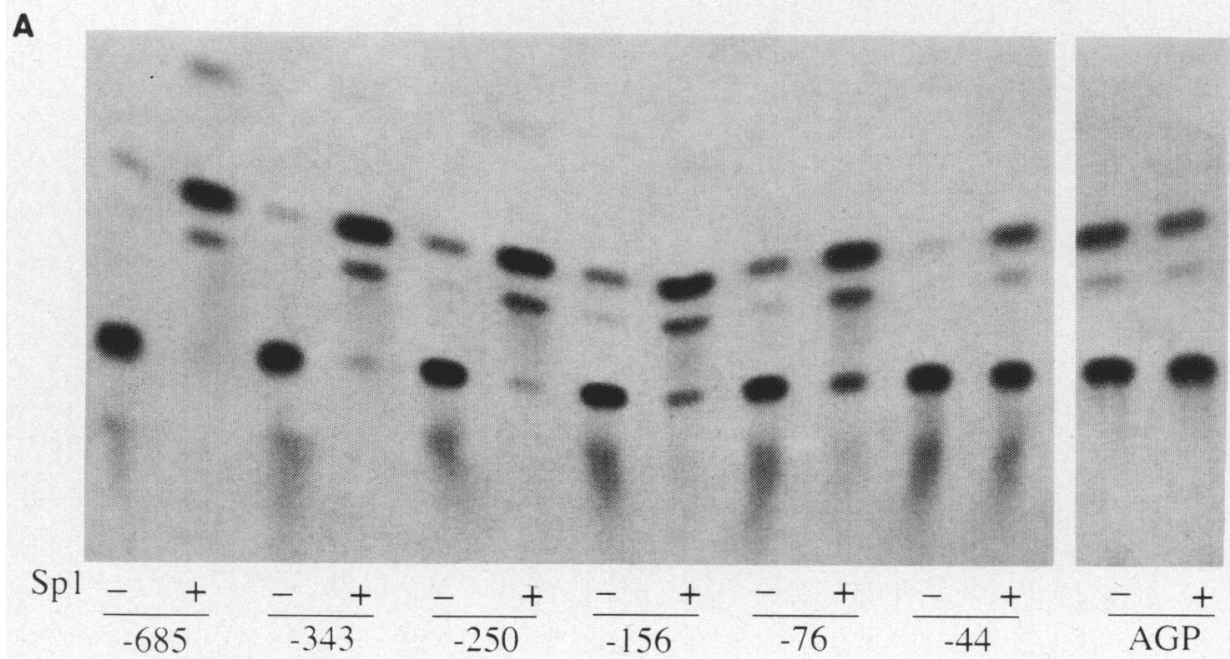

B

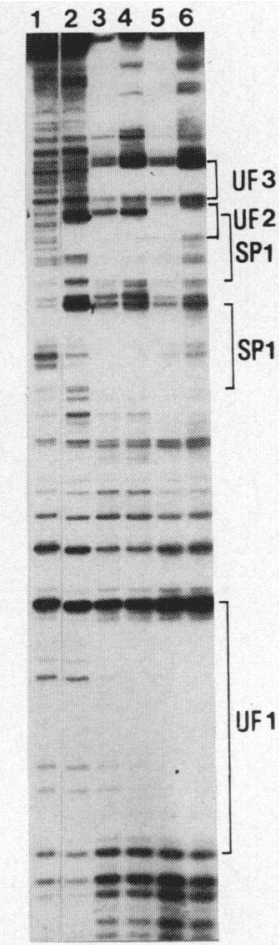

FIG. 7. Spl activates the AGP/EBP promoter. A. Schneider cell line SL. 2 was cotransfected with $3 \mu \mathrm{g}$ of CAT reporter linked to a series of AGP/EBP deletion promoter (AGP/EBP-CAT) and $0.25 \mu \mathrm{g}$ of pAcSpl expression vector. AGP-CAT was used as a control. B. DNase I footprinting experiments of AGP/EBP probe $(-390$ to +82$)$ and nuclear extract prepared from normal or LPS-stimulated mouse liver and purified Sp1. Lane 1, BSA control; lanes 2-6, $15 \mathrm{ng}$ of purified Sp1; lanes 3-4, 25 and $50 \mu \mathrm{g}$ of normal liver nuclear extract; lanes 5-6,10 and $20 \mu \mathrm{g}$ of LPS-liver nuclear extract.

\section{REFERENCES}

AKIRA, S., and KISHIMOTO, T. (1992). IL-6 and NF-IL6 in acute-phase response and viral infection. Immunol. Rev. 127, 25-50.

AKIRA, S., ISSHIKI, H., SUGITA, T., TANABE, O., KINOSHITA, S., NISHIA, Y., NAKA JIMA, T., HIRANO, T., and KISHIMOTO, T. (1990). A nuclear factor for IL-6 expression (NF-IL6) is a member of C/EBP family. EMBO J. 9, 1897-1906.

ALAM, T., AN, M.R., and PAPACONSTANTINOU, J. (1992). Differential expression of three C/EBP isoforms in multiple tissues during the acute phase response. J. Biol. Chem. 267, 5021-5024.

ALBERINI, C.M., GHIRARDI, M., METZ, R., and KANDEL, E.R. (1994). C/EBP is an immediate-early gene required for the consolidation of long-term facilitation in Aplysia. Cell 76, 1099-1114.

ANGEL, P., HATTORI, K., SMEAL, T., and KARIN, M. (1988). The jun proto-oncogene is positively autoregulated by its product, Jun/AP-1. Cell 55, 875-885.

CAO, Z., UMEK, R.M., and MCKNIGHT, S.L. (1991). Regulated expression of three $\mathrm{C} / \mathrm{EBP}$ isoforms during adipose conversion of 3T3-L1 cells. Genes \& Dev. 5, 1538-1552.

CHANG, C.J., CHEN, T.T., LEI, H.Y., CHEN, D.S., and LEE, S.C. (1990). Molecular cloning of a transcription factor, AGP/ EBP, that belongs to members of the C/EBP family. Mol. Cell. Biol. 10, 6642-6653.

CHEN, R., INGRAHAM, H.A., TREACY, M.N., ALBERT, V.R., WILSON, L., and ROSENTELD, M.G. (1990). Autoregulation of Pit-1 gene expression mediated by two cis-active promoter elements. Nature 346, 583-586.
CHRISTY, R.J., KAESTNER, K.H., GEIMAN, D.E., and LANE, M.D. (1991). CCAAT/enhancer binding protein gene promoter: Binding of nuclear factors during differentiation of 3T3-L1 preadipocytes. Proc. Natl. Acad. Sci. USA 88, 2593-2597.

DESCOMBES, P., and SCHIBLER, U. (1991). A liver-enriched transcription activator protein, LAP, and a transcriptional inhibitory protein, LIP, are translated from the same mRNA. Cell 67, 569-579.

DESCOMBES, P., CHOJKIER, M., LICHTSTEINER, S., FALVEY, E., and SCHIBLER, U. (1990). LAP, a novel member of the C/EBP gene family, encodes a liver-enriched transcriptional activator protein. Genes \& Dev. 4, 1541-1551.

ISSHIKI, H., AKIRA, S., SUGITA, T., NISHIO, Y., HASHIMOTO, S., PAWLOWSKI, T., SUEMATSU, S., and KISHIMOTO, T. (1991). Reciprocal expression of NF-IL6 and C/EBP in hepatocytes: Possible involvement of NF-IL6 in acute phase protein gene expression. New Biol. 3, 63-70.

KONIG, H., PONTA, H., RAHMSDORF, U., and HERRLICH, P. (1989). Autoregulation of fos: the dyad symmetry element as the major target of repression. EMBO J. 8, 2559-2566.

LEE, Y.M., TSAI, W.H., LAI, M.Y., CHEN, D.S., and LEE, S.C. (1993). Induction of liver alpha-1 acid glycoprotein gene expression involves both positive and negative transcription factors. Mol. Cell Biol. 13, 432-442.

LEGRAVEREND, C., ANTONSON, P., FLODBY, P., and XANTHOPOULOS, K.G. (1993). High level of the mouse CCAAT/ enhancer binding protein $(\mathrm{C} / \mathrm{EBP} \alpha)$ gene promoter involves autoregulation and several ubiquitous transcription factors. Nucleic Acids Res. 21, 1735-1742.

METZ, R., and ZIFF, E. (1991). cAMP stimulates the C/EBP- 
related transcription factors NFIL- 6 to translocate to the nucleus and induce c-fos transcription. Genes \& Dev. 5, 1754-1766.

NAKAJIMA, T., KINOSHITA, S., SASAGAWA, T., SASAKI, K., NARUTO, M., KISHIMOTO, T., and AKIRA, S. (1993). Phosphorylation at threonine-235 by a ras-dependent mitogenactivated protein kinase cascade is essential for transcription factor NF-IL6. Proc. Natl. Acad. Sci. USA 90, 2207-2211.

NISHIO, Y., ISSHIKI, H., KISHIMOTO, T., and AKIRA, S. (1993). A nuclear factor for interleukin-6 expression (NF-IL6) and the glucocorticoid receptor synergistically activate transcription of the rat alpha-1 acid glycoprotein gene via direct proteinprotein interaction. Mol. Cell. Biol. 13, 1854-1862.

PENN, L.J.Z., BROOKS, M.W., LAUFER, E.M., and LAND, H. (1990). Negative autoregulation of c-myc transcription. EMBO J. 9, 1113-1121.

POLI, V., MANCINI, F.P., and CORTESE, R. (1990). IL-6DBP, a nuclear protein involved in interleukin 6 signal transduction, defines a new family of leucine zipper protein related to $\mathrm{C} / \mathrm{EBP}$. Cell 63, 643-653.

SASSONE-CORSI, P., SISSON, J.C., and VERMA, I.M. (1988). Transcriptional autoregulation of the proto-oncogene fos. Nature 334, 314-319.

SCHONTHAL, A., BUSCHER, M., ANGEL, P., RAHMSDORF, H.J., PONTA, H., HATTONI, K., CHIU, R., KARIN, M., and HERRLICH, P. (1989). The Fos and Jun/AP-1 proteins are involved in the downregulation of Fos transcription. Oncogene 4, 629-636.

SERFLING, E. (1989). Autoregulation-a common property of eukaryotic transcriptional factors? Trends Genet. 5, 131-133.

TEN, R.M., PAYA, C.V., ISRAEL, N., LE BAIL, O., MATTEI, M.G., VIRELIZIER, J.L., KOURILSKY, P., and ISRAEL, A. (1992). The characterization of the promater of the gene encording the p50 subunit of NF- $\mathrm{BB}$ indicates that it participates in its own regulation. EMBO J. 11, 195-203.
THAYER, M.J., TAPSCOTT, S.J., DAVIS, R.L., WRIGHT, W.E., LASSAR, A.B., and WEINTRAUB, H. (1989). Positive autoregulation of the myogenic determination gene MyoD1. Cell 58, 241-248.

TRAUTWEIN, C., CAELlES, C., GEER, VEN DER, P., HUNTER, T., KARIN, M., and CHOJKIER, M. (1993). Transactivation by NF-IL6/LAP is enhanced by phosphorylation of its activation domain. Nature 364, 544-547.

VASSEUR-COGNET, M., and LANE, M.D. (1993). Trans-acting factors involved in adipogenic differentiation. Curr. Opin. Genet. Dev. 3, 238-245.

WEGNER, M., CAO, Z., and ROSENFELD, M.G. (1992). Calcium-regulated phosphorylation within the leucine zipper of C/EBPB. Science 256, 370--373.

WILLIAMS, P., RATAJCZAK, T., LEE, S.C., and RINGOLD, G.M. (1991). AGP/EBP(LAP) expressed in rat hepatoma cells interacts with multiple promoter sites and is necessary for maximal glucocorticoid induction of the rat alpha-1-1acid-glycoprotein gene. Mol. Cell. Biol. 11, 4959-4965.

WILLIAMS, S.C., CANTWELL, C.A., and JOHNSON, F. (1991). A family of C/EBP-related proteins capable of forming covalently linked leucine zipper dimers in vitro. Genes \& Dev. 5, 1553-1567.

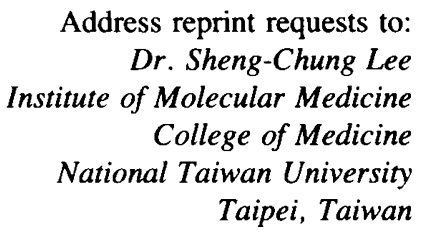

Received for publication November 25, 1994; accepted February 23, 1995. 